\title{
A former President reflects on the effects of social worker registration upon the Association: An interview with Rose Henderson*
}

\section{Rose Henderson with Kieran O'Donoghue.}

*The interview referred to in this article was transcribed and edited by Mary Nash and Kieran O'Donoghue, and approved by Rose Henderson.

Rose Henderson was President of Aotearoa New Zealand Association of Social Workers (ANZASW) for six years from 2003 to 2009. Prior to being President she was the National Secretary of ANZASW. This article is derived from an interview conversation between Kieran and Rose about her reflections as President during the implementation of the Social Workers Registration Act.

The conversation starts with Kieran asking Rose, 'What were the Association's aspirations for social worker registration?' Rose replied that she believed, 'The Association was very positive about the prospect of registration. The Association's project team had been involved with the development of the legislation and there was a sense that the principles established by the Association of ethical practice, competence and bicultural partnership would be furthered through the State regulating who could be a registered social worker.'

Following up on this Kieran asked, 'Whether there was an assumption that the Association's ethos would be transferred across into State registration?' To which, Rose replied, 'Yes, absolutely that was the view I and I believe others held at the time and, reflecting on it now, we were perhaps a little naïve in thinking that the professional body would be a key driver and key part of state regulation. Looking back now it is easy to see how registration and social worker regulation was an entirely different process that is controlled by the State and separate from the profession. I think that probably before the legislation we envisaged that the Association would have more involvement and influence upon social workers registration.'

The conversation then turned to Rose becoming President and the implementation of social workers' registration, and Kieran asked Rose, 'When did you take over as President?' To which Rose said, 'I became President at the 2003 AGM which followed the announcement of the inaugural Social Workers Registration Board (SWRB) on 5 November, 2003. My predecessor Robyn Corrigan stepped down as President and was appointed to the SWRB.'

Kieran then asked 'How did the relationship between the SWRB and the Association develop over the initial period following the Board's appointment?' Rose replied, 'We were really excited at the beginning, because there were stalwarts of the Association appointed to the inaugural Board and there was the hope and expectation that a lot of what the Association was hoping for regarding professional principles would be able to be embodied into the implementation of the legislative framework, in that first year. There was also a little 
bit of tension over the ownership of such things, for example, the professional standards of practice, code of ethics and ANZASW had begun their course approvals process. It was important from the Association's perspective, that our treasures were used appropriately and not simply taken over by the SWRB. We also wanted some recognition of the fact that they had been developed by the profession over many years. Notwithstanding this tension concerning the ownership of documents and the process to use documents, I think the inaugural Board did an amazing job at trying to develop the policies that would meet the regulatory and the professional needs. I recall that the Board gave the Association draft policies to consult on and liaised with us and that was a positive process. In summary, there were difficult conversations, but, looking back, at the end of the day, I think that a good foundation between the two bodies was established initially with both parties.'

Rose then discussed how ANZASW became the competency provider for the SWRB and said, 'The Association's competency programme had been operating for many years prior to registration so when registration arrived, the Association lobbied to be recognised as a competency provider under the Social Workers Registration Act (SWRA). The background to this was that in enacting the legislation, the Government wanted to ensure that people had a choice of competency provider. As a consequence, there was a lot of lobbying prior to legislation being enacted. For the Association this included the considerable amount of work done with Child Youth and Family (CYF), which resulted in CYF recognising the ANZASW competency process, rather than creating their own process. Following the recognition of the ANZASW competency by the SWRB, we entered new territory for us, as ANZASW entered into a contract for the provision of competency services to CYF. Prior to that point ANZASW had been an association that only serviced its members. We had not previously entered into a contract for the provision of services. It was a huge step for the Association to be a recognised provider, and new legal territory. Once people started getting registered the membership of ANZASW grew exponentially, because people were joining the Association principally for competency. At the time we (the Association) had hoped they were also joining because of the value of belonging to a professional body. I think there were, and remain, issues around people understanding the difference between the roles of a professional body versus a regulatory body. The Association has several times canvassed our membership about what people would like from their professional body, but certainly in those early days it was principally for competency that many new members joined.'

Kieran then raised the question 'How much choice did the Association have at the time regarding becoming a competency provider for registration, given it was core to membership of the Association?'

Rose responded, saying that, 'It was a position of little choice, we were trying, without capitalising on the opportunity, to advance, whilst always being aware that our primary focus was to provide a service for our members.' Rose then recalled how she felt extremely overwhelmed, daunted and anxious at the 2003 Annual General Meeting, by the fact that, 'The Registration Board, the new kid on the block, had appointed several of our key members and that was exciting for them to develop a new body'. She added that, 'The questions that the Association had to ponder at that time were: What did registration mean for the Association? What would be the impact on our livelihood and our membership etc...? It was a difficult time but certainly the competency contract and being recognised as a provider delivered a way for the Association and the SWRB to be mutually beneficial in a sense.' 
Kieran then said, 'You mentioned earlier that there has been some confusion about the respective roles of ANZASW and SWRB, I wonder if you would discuss this further?'

Rose responded, saying, 'There are still a lot of people who do not fully understand the role of a regulatory authority versus the role of a professional body. I am fortunate, through working in health, to have colleagues who are all registered and most also belong to professional bodies. In other words, there is a culture of understanding of the distinctive benefits and separate roles of both a professional body and a regulatory authority. It seems to me that for many other social workers, working in primary services, NGOs or other government departments that the difference between a professional body and a regulatory authority is not something they are as familiar with. For example, in tea room conversations, it is still common for people to speak about being 'registered' with the Association in the belief that this means they are a registered social worker and to be quite confused about making and understanding the distinction between belonging to the professional body as a member and being registered as a social worker with the SWRB. I know there have been many attempts by both bodies through roopu, branches and various other professional groupings and meetings to try and educate people about the different roles and drivers but I think there remains a continuing need for this to be promoted.

'To be fair, I think that some of the things that have happened over the last 10 years may not have helped and I do not want to blame either party for this. What I mean is that for some professions their registration authorities simply deal with the regulation of their profession. In other words, their work is primarily concerned with processing applications, authorising annual practising certificates and dealing with disciplinary matters including competency when competence is questioned, (which is different from social work competency which is a part of a criteria for membership of ANZASW and registration with SWRB). Our regulatory authority has become involved in providing competency because it is a criterion for registration (ie, competency, as opposed to assessing an individual's competence when it is in question). In addition, the SWRB seems also to be becoming involved in some professional development activities. Whilst I acknowledge that it is their right to do this, it is not helping people to understand the role and value of the different bodies that I believe should work to complement rather than compete with each other.'

According to Rose, 'Part of the problem is because we are in an environment of voluntary registration and because people can choose whether or not they become registered and / or choose whether or not they belong to the professional body. Some people are choosing to belong to the Association and not become registered, which means that the Association has needed to continue to provide a complaints resolution process for its non-registered members in order to protect the public. It is the voluntary nature of registration that probably remains the most contentious issue, because the Association which had a de facto self-regulatory role prior to State registration, continues to have to act in that role. Whereas, for other disciplines which share a code of ethics / code of practice, you do not have that blurring because in those other disciplines it is the regulatory body that generally manages the complaints processes. With mandatory registration, you are not able to use a protected professional title and hang your shingle up unless you are a registered practitioner and have a practising certificate.'

Rose added that, 'I understand why the Government of the day elected not to make social worker registration mandatory at the beginning, in order to provide time for the up-skilling 
of the workforce, but we are 10 years down the track and we are still in a voluntary registration environment and there does not appear to be any obvious moves to change that.'

At this point Kieran commented, 'Rose, you are highlighting a nuance that perhaps some people may not be aware of, namely, that there was self-regulation of social workers through the Association before the State became the regulator of social workers through the Social Workers Registration Board, and that both systems, that is self-regulation and State regulation are voluntary.'

Rose replied saying, 'So now we have several different kinds of social workers, we have social workers who are employed, not members of the Association and not registered, we have social workers who only belong to the Association, we have social workers who are only State registered and we have social workers who are both registered and belong to ANZASW. With such diversity it is difficult to see how the primary purpose of state regulation, ie, to protect the public, can possibly be achieved, because it only protects the public from those who are registered. Anyone can still become a social worker and call themselves a social worker because the title of social worker remains unprotected.'

The conversation then turned to Rose's views about mandatory registration and the protection of the title social worker, with Rose stating that she supported mandatory registration whilst also expressing concerns about its implementation. Regarding the latter, she said, 'I think had mandatory registration happened about the time of the first review in 2007, or soon after that, it would have been less complicated than it might be now. This is because as time goes on things change and the regulatory authority has become involved in other things. It then becomes more difficult for roles and responsibilities to change. On the other hand, one of the drivers for the Registration Board to become involved in these 'competing' activities might be to broaden their financial base and, if all social workers had to be registered, then that may allow them the financial security to focus on protecting the public and promoting the profession in its more usually understood terms like other regulatory authorities. This could enable a reduction of the SWRB involvement in some of the competitive things between the Association and the board and facilitate greater clarity for social workers and members of the public alike.

Kieran then said, 'Rose, if I have understood what you are saying this far, it seems that you are raising a couple of interesting ideas. One of them is interdependency between the Association and the SWRB, with the Association being the competency service provider to the Registration Board initially. The second idea that you have raised is that there is a degree of tension in the voluntary registration system, due to a territorial overlap between the Association and the SWRB in regard to the social work profession. I am wondering what happened to the Association when things changed over time for instance, when Te Kaiawhina Ahumahi (TKA) started providing competency assessments for the SWRB?'

Rose replied saying, 'Initially there was not a lot of change but then over time, as two providers of services to the regulatory board, we developed a service provider relationship, where we collaborated to try and support the intent of objective professional competency. But at that time, it seemed that some of the SWRB staff, did not necessarily understand the meaning of competency in the way ANZASW intended it to be and there were attempts by the SWRB, which we felt were dumbing down competency. Despite the Association and TKA 
being in competition for clients, we shared philosophical goals when it came to upholding the intent of the legislation as we understood it in relation to competency. So we developed a closer relationship with TKA than we had had in the past and there was quite a lot of support between the two organisations in terms of a peer service provider relationship to maintain competency standards. Around 2007, TKA ceased to be a provider and that was when the Registration Board decided they would become a provider. I have always had reservations about the regulatory body providing competency. I think there is a conflict of interest issue around that, which I do not know that they have necessarily recognised. Also there were some concerns about the assessment process itself perhaps not being as robust or professionally objective as the Association had striven to uphold. In short, you have the Association as one of the original approved service providers to SWRB and the SWRB who approve competency providers then becoming a provider itself and being in competition with its own contracted provider.'

'Another area of challenge for the Association was in regard to approval of social work courses, wherein huge amounts of work had gone into developing an ANZASW process. I was frustrated that the SWRB seemed completely unwilling right from the beginning to engage in constructive conversations with the Association around the approval of courses. I do not know what the reason was for this situation as I was never able to get a satisfactory explanation about that. The SWRB took the position that it was their role in the legislation and they would do it. The Association pointed out that it potentially said that about competency as well, but ANZASW had a relationship whereby the SWRB recognised us as a provider, but they did not engage in meaningful conversations to progress course approvals at all. I do know we (the ANZASW) had huge support from the Association in Australia at that time, because course approvals had been something that was very dear to the Australian Association (AASW) and whilst we had become involved in this more recently we were nonetheless developing our systems and processes. It was certainly a significant disappointment at that time and because of the SWRB decision we were unable to continue to develop it. The big issue, apart from the loss and the frustration and the work that had been done, was the State taking over the defining of standards for professional education. The Association felt really strongly that it was the role for the profession to be approving social work education courses, not a regulatory body that is an arm of the Government dictating what will be provided in a professional qualification at a tertiary institution. There are other mechanisms for the State to have input into tertiary providers and for the profession to be excluded from contributing to the defining of the professional needs of social work students. I think that has definitely been one of the big losses for the profession.'

Kieran then said, 'An area that would seem related to this would be development of graduate competence by the SWRB which came in about 2008-9, and I am wondering what your thoughts are regarding this.'

Rose said, 'My personal reflection on this matter is that I have difficulty with a blurring between educational qualifications and competency to practise. I do absolutely understand why that has been done and why that potentially makes a transitional pathway relatively smooth. I think there could have been other ways to do that to preserve the integrity of what I believe are two separate and different criteria - qualification and competency. Competency includes the application of theory into professional practice, and whilst practicum placements 
may begin to do this they are a part of the academic, tertiary provider-assessed components of the qualification rather than a separately peer-reviewed professional assessment of competency in the broader sense and as such are two separate criteria being merged. I think there are other ways of measuring beginning competence rather than just having an automatic tick for completing your academic qualification.'

At this point Kieran said, 'Perhaps if we discuss now how did the Association support the aspirations of Maori in the registration environment?'

Rose responded saying, 'That is a really good question, because it was a significant issue right from the start. Within the legislation, the lack of recognition of the Treaty of Waitangi was regarded as a significant weakness if you like and we had submitted on that all along, but the Government at that time was not willing to embody that into the Act.

'Prior to registration ANZASW developed the Niho Taniwha model of competency, as a key part of ANZASW's competency programme to support Maori social workers through a kaupapa Maori framework for achieving competency (and potentially registration) through that competency process.

'It would be interesting to do some research on the number of Maori social workers who are registered and if they are not registered if there are any issues around that. It would be also interesting to explore the perceptions of both ANZASW Takawaenga O Aotearoa and the Tangata Whenua Social Workers Association, of registration 10 years on, because it seems very much a white, pakeha piece of legislation from a predominately white, pakeha Government. The professional body and many other parts of the profession try to preserve their commitment to a bicultural kaupapa. Yet it remains very light in the legislation.'

Kieran then asked, 'On that note I am wondering what amendments to legislation would you like to see, going forward?'

In reply Rose said, 'That is a good and difficult question. If we knew then what we know now, I would think differently about competency because it feels as though competency which people in the Association had developed and sweated blood and tears over, and was such an important part of it, it feels like it has to some degree been dumbed down, so maybe it would have been better to have kept that separate somehow, but of course the risk could have been it might have been totally lost earlier so I don't know. Certainly something that enshrined a commitment to bicultural practice would be something we would continue to assert and without a doubt the whole non-mandatory situation is still a big issue. We only got the Act over the line because it was not mandatory; there was not the political support to make it mandatory. So looking back perhaps, we should have held out and said no, sorry, that is just a waste of time, we are going to hang on and wait until we can achieve mandatory registration. Yet, as a health professional, I am committed to mandatory registration that is the norm in our field, it is how we function and many health providers have policies in place to support the regulation of their social work staff. However, this is not universal and, going back to what we discussed before, voluntary regulation gives no assurance that the public are being protected when seeing a social worker, because they might not be registered, might not belong to a professional body, may not have any professional accountability so the current status doesn't cut the mustard for protection of the public.' 
Kieran then asked Rose about the relationship between the Health Practitioners Competency Assurance Act and the SWRA and whether any progress had been made in the last 10 years for health social workers.

In response to this Rose said, 'That is a really good question because prior to the Social Work Registration Act coming into force, the health workers had lobbied really hard for health social work to be under the Health Practitioners Competence Assurance Act (2003) (HPCA) and we know the reasons why that didn't happen. In the health system it is a significant anomaly. Most other health professionals are regulated by the HPCA and understand that, and then there is social work, outside of the HPCA. In my current role in my DHB I am constantly talking to people who do not understand this, helping them to understand the difference. I guess over time it is starting to be more generally understood although the impact of this across other government departments remains significant where they recognise health professionals under the HPCA but the role of health social work (e.g. in counselling or rehabilitation) is not recognised.

'However, it is also about the way regulation is operationalised. Other professions have to be registered with the HPCA before we even employ them. Social workers come in and in my DHB we now have a raft of conditions on their employment such as one of the conditions is that they will complete their application for registration within three months of their start time, but we cannot require them to be registered within three months because the Registration Board only meets every three months and that is incomprehensible to other professionals. So the system for becoming a registered social worker is in my view not as efficient and as effective as it might be, because I say to my medical and other colleagues, we cannot make them be registered within this amount of time, because the SWRB does not meet that often and if they need to get extra information, that is another three months, and I have to say that does raise the eyebrows of other health professionals. It would be different if we were under HPCA, because their processes would be a bit different. Social work is so much more complicated than any other profession; we really make it hard for ourselves.'

The conversation then turns to the changes that had occurred within the Association, over the last 10 years, with Kieran asking Rose for her reflections on these changes. Regarding these Rose commented that, 'During this period there was a growing body of knowledge, and issues around the governance and management of organisations and a number of things had gone wrong in agencies where governance and management had not been well-defined, and well separated. As an organisation, the ANZASW was growing very quickly. We had enormous numbers and our systems and processes needed to evolve to keep up, so the Association embarked on a revised structure with a more defined governance management split and that was a painful process in many ways. There was the loss of things, like the National Council when delegates from all around the country came to meet together and I think it is a shame that there is no longer a mechanism to enable that to happen biannually. Though I would not want to suggest that what we had was perfect! We did have representatives from around the country coming together, but we possibly did not use that expertise as well as we might have in terms of developing, reviewing and continuing to grow the profession, key policies etc... And of course you often ended up with the same people coming all the time because in small roopu or branches it might only have been one or two people who were regularly engaged at that level, although there might have been 50 or 100 other members in that area who were not engaged, so was that a representative view? It is not an easy 
one, but I do think we lost something by not being able to maintain this connection with all the roopu and branches and to some degree now the branches and roopu may perhaps be less active than they used to be. I think that was a major change, and in hindsight it was perhaps a pity that we have not found a way to successfully maintain the benefits of the council meetings. I know the Association still has or did have one annual forum that brought people together and that did have the possibility of different think tanks on different topics, or interest groups' development and policy development. That was an attempt to replace the National Council with another vehicle. I am not sure how this is continuing to evolve. Maintaining links with the members and supporting the branches and roopu to maintain some healthy existence has always been a challenge and probably continues to be.'

The conversation draws to a close with Rose reflecting on the discussion about the last 10 years and saying that, 'For the first part of the period my experiences were drawn from my role as President of the Association and more recently it has been as an employer of social workers in the health system. I have had different views about registration over that time. I am committed to regulation of the profession and I have strongly advocated that our workforce is fully regulated. I am sorry that it is not mandatory and I am sorry that there continues to be blurring of roles of the professional body and the regulatory authority, and I would like to think that there would be a way of being able to separate those out more cleanly and get professional social workers to clearly understand the role of the different bodies.

'Regarding the Association's journey, to be fair, I cannot comment on the last few years. But from the beginning, it was a nervous new relationship for the ANZASW with the SWRB. As an Association we were nervous about the impact on the professional body, that this new relationship with the new authority would have. Then we entered into a phase of huge growth and it was really busy and we could hardly keep up with the changes and the impact of those changes. It was also very exciting because we were no longer having to sit around a table thinking are we going to be able to have a meeting next month, because there was more cash flow, which enabled us to develop more services and more opportunities, and then it plateaued for a while and now it has dropped off. I imagine that probably there is still that nervousness and tension about the survival, role and purpose of the Association and so, in some ways, the more things change the more they stay the same. But obviously in a different way to what it was back then. I think one very positive thing that has grown has been the public voice, so there has been a lot more active involvement of ANZASW in making submissions and making comment. Of course not all comment is picked up by the media, and it probably has waxed and waned over time, but I think in general there has been a lot more of that and that's been really good. I think there are still on-going questions. I have no idea what the current relationship is between the ANZASW governance board and the SWRB, and I am not observing any improved clarity and differentiation between the two bodies. Perhaps there have been changes, but I have not observed a clear articulation and a distinct differentiation between the two.' 